\title{
Replication-competent herpes virus NV1020 as direct treatment of pleural cancer in a rat model
}

\author{
Michael I. Ebright, MD \\ Jonathan S. Zager, MD \\ Sandeep Malhotra, MD \\ Keith A. Delman, MD \\ Tracey L. Weigel, MD \\ Valerie W. Rusch, MD \\ Yuman Fong, MD
}

From the Department of Surgery, Memorial Sloan-Kettering Cancer Center, New York, NY.

Supported in part by training grant T32 CA 09501 (M.I.E.) and US Public Health Service grants RO1CA75416, RO1CA72632, and RO1CA61524 from the National Institutes of Health and MBC-99366 (Y.F.) from the American Cancer Society.

Read at the Eighty-first Annual Meeting of The American Association for Thoracic Surgery, San Diego, Calif, May 6-9, 2001.

Received for publication May 14, 2001; revisions requested Aug 21, 2001; revisions received Nov 27, 2001; accepted for publication Dec 12, 2001.

Address for reprints: Yuman Fong, MD, Department of Surgery, Memorial SloanKettering Cancer Center, 1275 York Ave, New York, NY 10021 (E-mail: fongy@ mskcc.org).

J Thorac Cardiovasc Surg 2002;124:123-9

Copyright ( $(2) 2002$ by The American Association for Thoracic Surgery

$0022-5223 / 2002 \$ 35.00+0 \quad \mathbf{1 2 / 6 / 1 2 2 2 9 7}$

doi: $10.1067 / \mathrm{mtc} .2002 .122297$
Objective: Innovative treatments are needed for metastatic disease involving the pleura. NV1020 is a novel, multimutated, replication-restricted herpes simplex virus under investigation for its ability to selectively kill tumors by means of direct cell lysis. This study examines NV1020 in a rat model of pleura-based lung cancer.

Methods: Cytotoxicity and viral proliferation were evaluated in vitro by exposure of the human non-small cell lung cancer cell line A549 to virus. NV1020 was also tested in an in vivo pleura-based cancer model established by injecting $1 \times 10^{7}$ A549 cells into the thoracic cavity of nude rats. Intrapleural treatments $\left(1 \times 10^{7}\right.$ viral particles) were given 3 hours or 3 days after tumor injection to model treatment of microscopic or macroscopic disease ( $n=8-9 /$ group). Tumor burden was assessed at 5 weeks. NV1020 infection and dissemination within the thoracic cavity was determined by means of immunohistochemistry.

Results: In vitro, at multiplicities of infection (viral particles per tumor cell) of 0.01, 0.1 , and 1.0, cell killing of A549 by NV1020 was $66 \%, 90 \%$, and $97 \%$, respectively, at 7 days after infection. Viral burst occurred by day 2 . Intrapleural treatment was effective for both the microscopic $(P<.001)$ and macroscopic $(P<.05)$ in vivo tumor models. Virus was detectable by means of immunohistochemistry in tumors but not in adjacent normal intrathoracic tissues.

Conclusions: NV1020 is not only highly cytotoxic to the human lung cancer line A549 in vitro but can be delivered in a clinically relevant fashion to safely and effectively treat pleura-based tumor in vivo in a rat model.

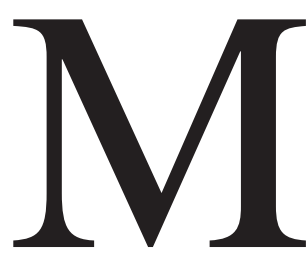

etastatic disease of the pleura is a common and significant management problem for the thoracic oncologist. This occurs most frequently in patients with locally advanced or disseminated cancer but occasionally occurs as a disease of unknown primary cause. The pleural tumor itself usually manifests as a malignant effusion but can also present as a pleura-based mass. The most common causes are lung, breast, ovarian, and lymphoid cancers. ${ }^{1,2}$ Unfortunately, systemic chemotherapy has a poor response rate in these malignant tumors. Several chemotherapeutic agents have been used to treat pleural disease by means of intrapleural administration, with no more than modest success. ${ }^{3,4}$ As a result, new therapeutic modalities are needed to control this condition.

Oncolytic viral therapy is an exciting and promising new method of cancer treatment. Genetically, modified herpes simplex type 1 virus (HSV-1) has been shown to selectively replicate within and lyse malignant cells while sparing normal tissue and are under investigation as treatment for tumors of the brain, colon, 
stomach, prostate, ovary, head, and neck, as well as a peritoneal model of malignant mesothelioma. ${ }^{5-11}$ NV1020 is an attenuated, replication-competent HSV-1 virus originally designed for herpes vaccine studies that is currently being explored as an oncolytic viral therapy. Multiple genetic modifications render NV1020 less virulent in normal tissue, yet it maintains the capacity to infect, replicate within, and lyse malignant cells. Several genes, including the $U_{\mathrm{L}} 24$ gene and one of two copies of the $\gamma_{1} 34.5$ gene have been deleted to attenuate neurovirulence. $6,9,12$

Several models of pleural metastatic disease have previously been developed in the mouse that are assessable mainly by tumor-related mortality. ${ }^{13-15}$ In the current study we describe the development of a model of metastatic pleural disease in the rat that allows assessment of tumor burden and extent of viral dissemination, as well as mortality. Using this model, the current study explores the utility of NV1020 for the treatment of metastatic disease to the pleura.

\section{Materials and Methods Cells}

The human lung adenocarcinoma cell line A549 was obtained from the American Type Culture Collection (Rockville, Md) and was maintained in Ham's F-12 medium containing $10 \%$ fetal calf serum, $100 \mu \mathrm{g} / \mathrm{mL}$ penicillin, and $100 \mu \mathrm{g} / \mathrm{mL}$ streptomycin. Cells were maintained in a $5 \%$ carbon dioxide humidified incubator at $37^{\circ} \mathrm{C}$. Cell viability for all experiments was greater than $95 \%$, as determined by means of trypan blue exclusion.

\section{Virus}

NV1020 (gift of Medigene Inc, San Diego, Calif) is an attenuated, replication-competent derivative of HSV-1. ${ }^{16} \mathrm{NV} 1020$ is a nonselected clonal derivative from R7020, a candidate HSV-1/2 vaccine strain, obtained from Dr B. Roizman. ${ }^{17}$ The structure of NV1020 is characterized by a $15-\mathrm{kb}$ deletion encompassing the internal repeat region, leaving only one copy of the following genes, which are normally diploid in the HSV-1 genome: ICPO, ICP4, the latency associated transcripts, and the neurovirulence gene $\gamma_{1} 34.5$. A fragment of HSV-2 DNA encoding several glycoprotein genes was inserted into this deleted region. In addition, a 700-bp deletion encompasses the endogenous thymidine kinase locus, which also prevents the expression of the overlapping transcripts of the $U_{\mathrm{L}} 24$ gene. An exogenous copy of the gene encoding HSV-1 thymidine kinase was inserted under control of the $\alpha 4$ promotor. Virus was propagated in vero cells and harvested by means of freeze-thaw lysis to release virus from the cell fraction. Cell lysates were clarified by means of centrifugation, and viral titers were determined on vero cells by means of plaque assay. All virus preparations were formulated in D-phosphate-buffered saline solution (PBS) $-10 \%$ glycerin and stored at $-80^{\circ} \mathrm{C}$.

\section{Animals}

All animal work was performed with the prior approval of the Memorial Sloan-Kettering Institutional Animal Care and Use Committee. Athymic male rats 6 to 8 weeks old were purchased from the National Cancer Institute (Bethesda, Md). Animals were subjected to a 12:12-hour light/dark cycle, housed 2 per cage, and allowed food and water ad libitum.

\section{In Vitro Cytotoxicity}

The ability of NV1020 to infect and lyse A549 cells in vitro was assessed. Cells were plated at $5 \times 10^{4}$ cells/well in 12 -well plates (Corning Inc, Corning, NY) and were infected with NV1020 at multiplicities of infection (MOI) of 0.01, 0.1, and 1.0. Control wells were treated with culture medium alone. Cell viability was assessed by counting live cells through trypan blue exclusion at 24-hour intervals carried out to 7 days. All assays were performed in triplicate.

\section{In Vitro Viral Proliferation}

A viral growth curve was established to demonstrate viral replication in A549 cells. Cells $\left(5 \times 10^{4}\right)$ were plated in 6-well plates (Corning Inc) and infected with NV1020 at an MOI of $1.0(5 \times$ $10^{4}$ plaque-forming units [PFU]). Cells and supernatants were harvested daily for 5 days after infection. Three cycles of freezethaw lysis were performed, and viral titers were determined by means of standard plaque assay with vero cells. All infections were performed in triplicate.

\section{Establishment and Treatment of Pleural Tumor in \\ Rats}

A cellular suspension of A549 was implanted in the thorax of athymic rats, as previously described. ${ }^{18}$ Anesthesia was induced by means of a single intraperitoneal injection of pentobarbital (50 $\mathrm{mg} / \mathrm{kg}$ ). Rats were placed in the right lateral decubitus position. The left chest was shaved and prepared with $10 \%$ povidone-iodine solution. A 2-cm skin incision was created over the fifth or sixth intercostal space. Sharp dissection was carried out through the muscle layers anterior to the latissimus dorsi. A number 10 scalpel was used to carefully shave away the intercostal muscles, exposing the parietal pleura without breaching it. The underlying expanding lung was thereby easily visualized through the thin membrane. Three hundred microliters of A549 cellular suspension $\left(1 \times 10^{7}\right.$ cells) was slowly injected through the pleura with a 27 -gauge needle. Puncture of the lung was easily avoided because the needle tip was clearly observed to be superficial to the lung surface during injection through the transparent parietal pleura. After injection, the muscle layer was reapproximated with interrupted 4-0 nylon sutures, and the skin was closed with surgical staples. Recovery was observed for 2 hours before the rats were returned to their cages.

Intrapleural treatment with virus was performed in a similar fashion either 3 hours or 3 days after tumor implantation. NV1020 $\left(1 \times 10^{7} \mathrm{PFU}\right)$ was administered in $300 \mu \mathrm{L}$ of PBS. Control animals were treated with an equal volume of PBS. For intravenous treatment, the same dose of virus was administered in $1 \mathrm{~mL}$ of PBS by means of penile vein injection. Rats were regularly assessed for weight loss and tachypnea throughout the experimental period. Rats were killed, and all visible tumor in the chest was excised to quantify tumor bulk at 5 weeks after implantation. Total tumor weight was assessed.

In the first experiment the ability of NV1020 to treat freefloating microscopic disease was assessed. Twenty-seven rats $(\mathrm{n}=$ 


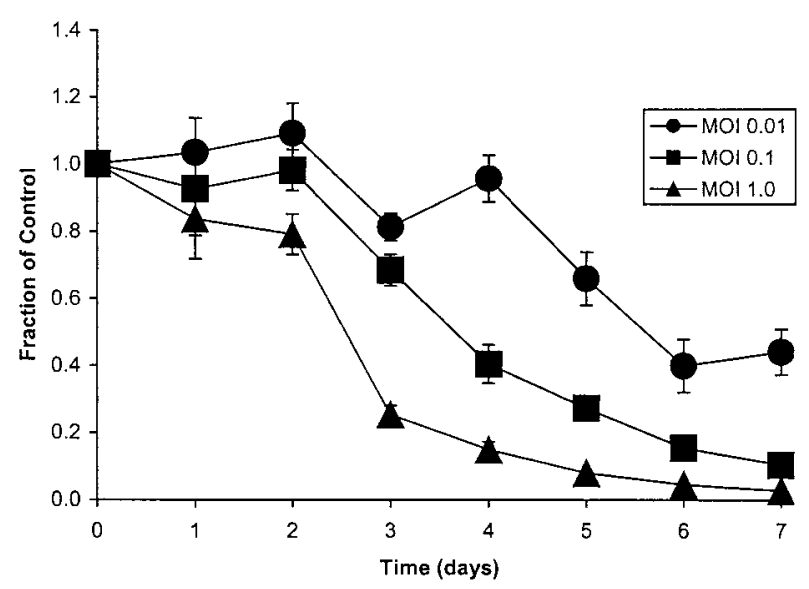

Figure 1. In vitro cytotoxicity of NV1020 against A549 cells expressed as a fraction of control. Cell counts were measured daily for 7 days. Assays were performed in triplicate, and error bars indicate SEM.

9/group) were injected with A549 into the pleural space, and chest incisions were closed. Three hours later, rats were treated with either intrapleural PBS, intrapleural NV1020, or intravenous NV1020. Five weeks later, the animals were killed and intrapleural tumor weight was determined. In a second experiment NV1020 was evaluated for the treatment of macroscopic pleural disease. Two groups of rats ( $\mathrm{n}=8$-9/group) were implanted with A549 and treated 3 days later. Two additional rats were injected with tumor and killed at 3 days to verify the presence of macroscopic disease.

\section{Histologic Analysis of the Extent of NV1020 Infection} and Dissemination in Vivo

Control animals with no pleural tumor and animals with 4-weekold A549 tumors within the pleural cavity were injected with virus ( $n=3$ /group) to assess for viral dissemination in tumor and in noncancerous tissues. Three days later, rats were killed, and intrathoracic tissues were harvested. Tissues (tumor, heart, lung, chest wall, and diaphragm) were fixed in $4 \%$ paraformaldehyde and embedded in paraffin with a tissue processor (TP1050; Leica Microsystems, Deerfield, Ill). Eight-micrometer paraffin sections were stained immunohistochemically to assess the presence of HSV-1 by using a polyclonal rabbit anti-HSV antibody (No. PU084-UP; Biogenex, San Ramon, Calif) in conjunction with the ABC Elite kit (Vector Labs, Burlingame, Calif) detection system. Sections were counterstained with Gill's hematoxylin solution, dehydrated, and mounted in Permount mounting medium (ProSciTech, Kelso, Australia).

\section{Results}

\section{In Vitro Cytotoxicity}

The oncolytic efficacy of NV1020 against A549 cells in vitro was assessed. Viable cells remaining over time (as a fraction of control) are demonstrated in Figure 1. Significant cell lysis begins 48 hours after infection. By day 7, NV1020 killed $66 \%, 90 \%$, and $97 \%$ of tumor cells at MOI levels of

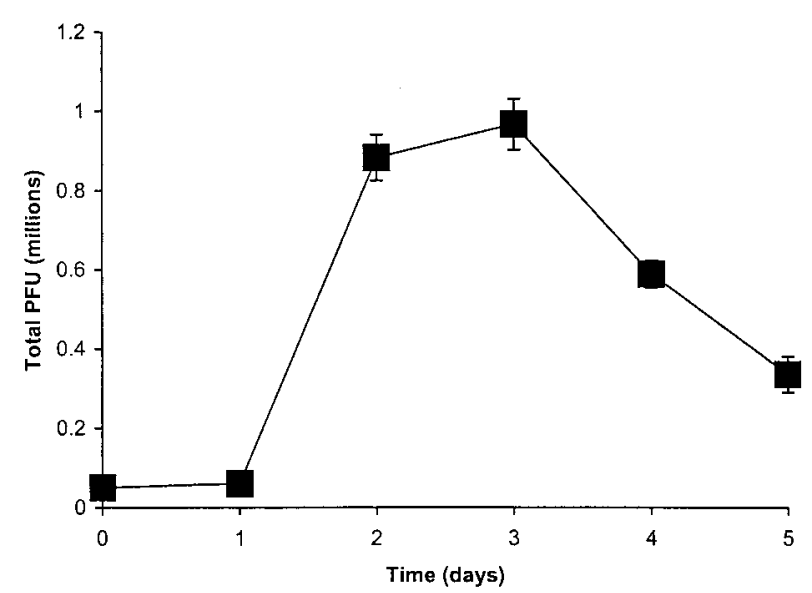

Figure 2. NV1020 replication in A549 cells after in vitro infection with an MOI of 1.0 ( $\left.5 \times 10^{4} \mathrm{PFU}\right)$. Viral titers were evaluated by means of standard plaque assay. Assays were performed in triplicate, and error bars indicate SEM.

$0.01,0.1$, and 1 , respectively. A clear dose-response relationship exists. Similar results were seen with the human lung squamous cell H157 (data not shown).

\section{In Vitro Viral Proliferation}

Cells were infected at an MOI of $1\left(5 \times 10^{4} \mathrm{PFU}\right)$ to assess the ability of A549 to permit viral replication. Virions were recovered from both supernatant and cells and titered daily over 5 days (Figure 2). By 48 hours, a viral burst occurred, producing a 17 -fold increase in viral titer $\left(8.8 \times 10^{5} \mathrm{PFU}\right)$. This burst activity corresponds to the sharp decline in viable cells observed at day 3 in the cytotoxicity curve.

\section{Treatment in Rat Model of Microscopic Pleural Tumor}

Animals were treated 3 hours after injection of tumor cells to evaluate the efficacy of NV1020 for the treatment of free-floating microscopic disease. By 5 weeks, control animals had bulky disease, with the largest nodules $(1-5 \mathrm{~mm})$ on the pleura and pericardium. In several cases the diaphragm was partially replaced with tumor. The internal chest wall also exhibited large tumor nodules. Smaller nodules were occasionally seen on the surface of the heart and lungs $(<1 \mathrm{~mm})$. A nonbloody pleural effusion was present in 3 of 9 animals in the control group. Disease was limited to the thoracic cavity. At death, extrathoracic organs (brain, liver, spleen, kidney, retroperitoneum, and spine) showed no evidence of macroscopic disease on sectioning. Direct injection of NV1020 into the pleural cavity significantly suppressed tumor growth and completely prevented tumor growth in 5 of 9 animals (Figure 3). Mean \pm SEM tumor weight in the control group was $2.07 \pm 0.51 \mathrm{~g}$ compared with $0.02 \pm 0.01 \mathrm{~g}$ in the intrapleural treatment group $(P<$ 


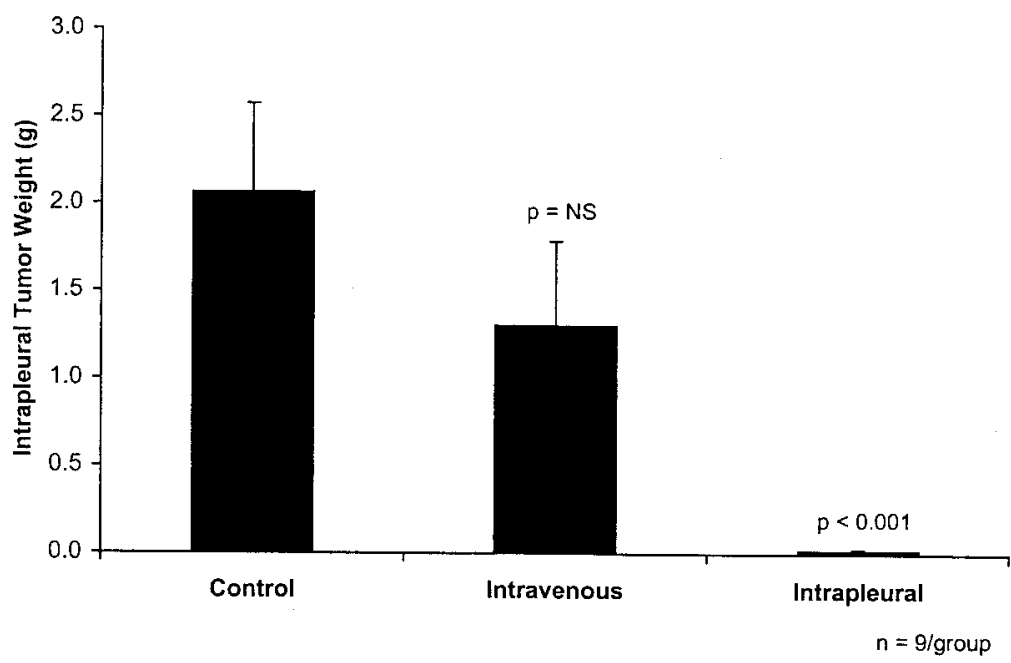

Figure 3. Mean intrapleural tumor weight in rats treated 3 hours after tumor inoculation. Rats were treated with intrapleural PBS, intravenous NV1020 (1 $\times 10^{7}$ PFU), or intrapleural NV1020 (1 $\times 10^{7}$ PFU). Error bars indicate SEM. The $\boldsymbol{P}$ value for the intravenous treated group is .29 , and that for the intrapleural group is .001 .

.001). Intravenous therapy, however, had no significant effect of reducing tumor burden (mean tumor weight, $1.30 \pm 0.48 \mathrm{~g}$ ). Animals in all 3 groups gained weight throughout the experimental period without exhibiting tachypnea or other outward signs of distress.

\section{Treatment in a Rat Model of Macroscopic Pleural Tumor}

Two animals were killed 3 days after A549 cells were injected into the pleural space to document the presence of tumor implantation and macroscopic pleural disease at 3 days after inoculation. Multiple small $(0.5-1.0 \mathrm{~mm})$ nodules were grossly visible on the pleura, chest wall, and diaphragm, as well as within the mediastinal fat. Tissues were fixed, and sections were stained with hematoxylin and eosin for microscopic confirmation (Figure 4, A-C). On microscopic evaluation, tumor was also detected in the mediastinal fatty tissue.

Rats inoculated 3 days prior with intrapleural A549 were treated with either intrapleural NV1020 $\left(1 \times 10^{7} \mathrm{PFU}\right)$ or intrapleural PBS to evaluate the ability of the virus to treat implanted, macroscopic disease. The rats were killed 5 weeks later, and tumor burden was assessed. Animals treated with intrapleural virus had significantly less tumor burden than control animals $(P<.05$, Figure 5). Mean \pm SEM tumor weight in the control group was $1.02 \pm 0.44 \mathrm{~g}$, and mean tumor weight in the treated group was $0.23 \pm$ $0.20 \mathrm{~g}$. A nonbloody pleural effusion developed in 2 of 8 rats in the control group. In the treated group 4 of 9 rats had no tumor.
Immunohistochemical Analysis of Thoracic Tissues

Three rats were inoculated with A549 cells and injected with intrapleural NV1020 4 weeks later. Three days after NV1020 injection, at the peak of viral proliferation (as determined by prior studies), rats were killed, and intrathoracic tissues and tumor were harvested. ${ }^{6}$ In all 3 rats, tumor specimens displayed immunohistochemical evidence of the presence of viral antigen (Figure 4,D). Positive staining for viral antigen progressed beyond the surface to involve cell layers deep in the tumor. Normal tissues tested were lung, heart, diaphragm, and internal chest wall. Viral presence was not detectable in any of these normal tissues in any of the 3 animals. Of note, the neurovascular bundles in these organs also did not demonstrate any staining for virus. In animals that were not administered tumor cells, viral presence was also undetectable in all of the normal tissues after viral treatment.

\section{Discussion}

Malignant disease of the pleura is associated with a grim prognosis, with most patients surviving only a few months after diagnosis. ${ }^{19}$ The most common cause is lung cancer, comprising $35 \%$ to $40 \%$ of all malignant effusions. ${ }^{1,2,20}$ The majority of cases are adenocarcinoma by histotype. ${ }^{2}$ Chemical sclerosing agents are often administered to obliterate the pleural space to treat the effusions accompanying tumor at this site that result in shortness of breath, but they do not address the underlying disease. Interest in intrapleural administration of chemotherapeutics has been driven by the theoretical advantage of treating local and regional disease in addition to palliating the effusion. Several groups, with varied success, have explored intrapleural chemotherapy 

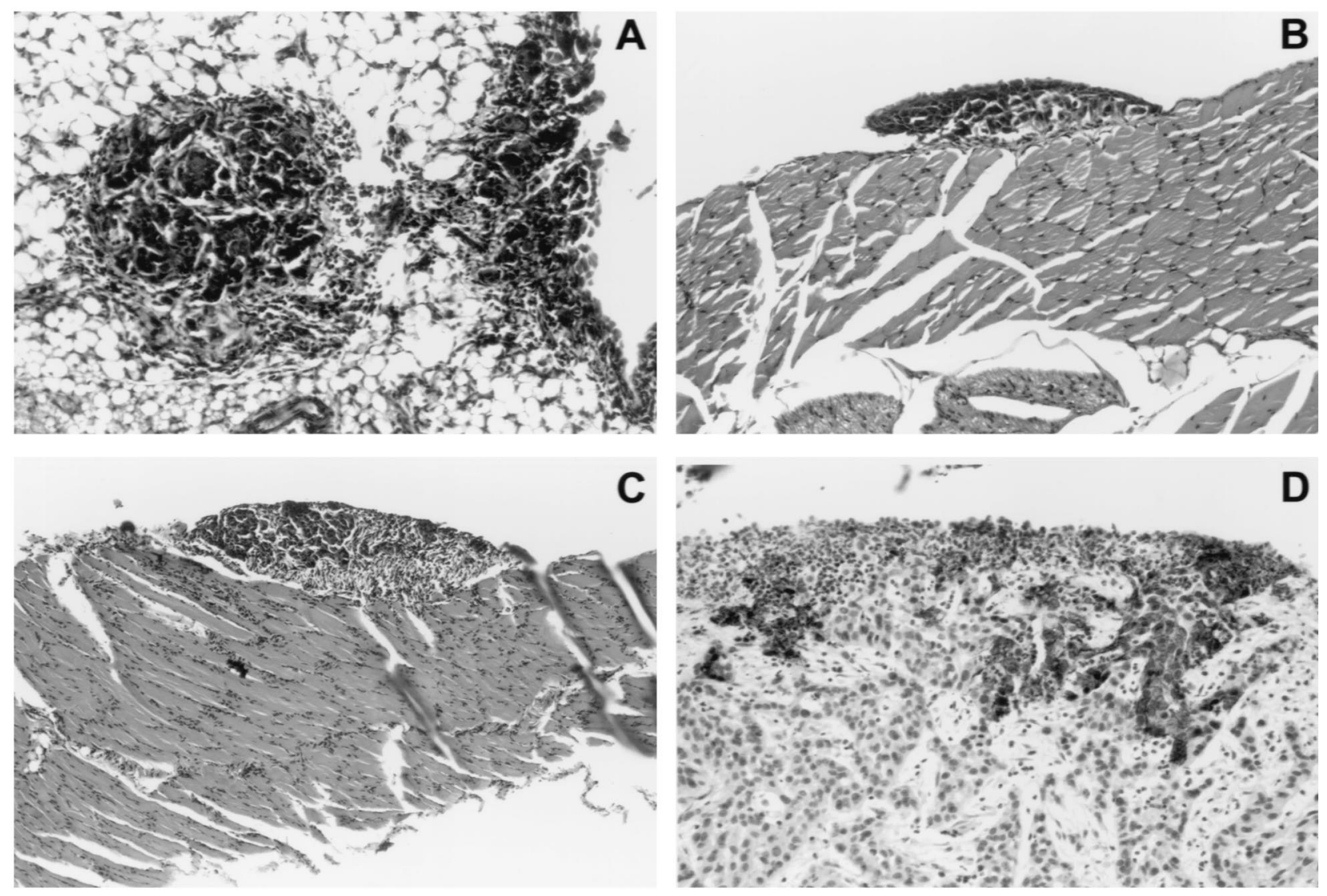

Figure 4. Representative sections of tumor implants evident 3 days after intrapleural tumor inoculation. Shown are samples from mediastinal fat (A), chest wall (B), and diaphragm (C). (Original magnification 20×.) D is a representative section of pleural tumor from rats treated with intrapleural virus $\mathbf{7 2}$ hours earlier. Sections were analyzed by means of immunohistochemistry with a polyclonal anti-HSV primary antibody. Brown cells are positive for viral antigen.

with assorted agents. ${ }^{3,4}$ None of these cytotoxic agents has proven as effective for palliation as the sclerosants. In addition, the disadvantages of pain, fever, organ toxicity, and high cost have decreased enthusiasm for these treatments. There is clearly a need for the development of novel therapies for metastatic disease of the pleura.

Biologic therapies are promising alternatives currently being explored for the treatment of thoracic malignancies. Gene-replacement therapy (p53 specifically), suicide gene therapy (using the HSV $t k$ gene and ganciclovir), and immunogenetic therapy are some examples of these new approaches to cancer treatment. ${ }^{21}$ These approaches have not yet met with major success. Oncolytic viral therapy, on the other hand, uses the natural ability of replication-competent HSV-1 to infect and lyse target cells. Several attenuated mutants have been developed, which preferentially infect tumor cells while sparing normal tissue. The theoretical advantage of using a replication-competent virus is that only a fraction of tumor cells need be infected initially before the virus propagates in permissive cancerous tissue.
NV1020 is an HSV-1 oncolytic virus highly attenuated for neurovirulence yet replication competent in tumor cells. The basis for this attenuation is not completely understood but is likely caused by the deletion of several wild-type genes, including a single copy of $\gamma_{1} 34.5$, as well as $U_{\mathrm{L}} 56$ and $U_{\mathrm{L}} 24$. NV1020 has proven safe in primate studies when delivered in doses over 10,000 times higher than the known lethal dose of wild-type HSV-1. ${ }^{12}$ Several added measures of safety also exist because of the structure of this virus. Because NV1020 is a multimutated virus, the chance of spontaneous reversion is extremely remote. ${ }^{17}$ Also, because of the presence of the gene encoding thymidine kinase, NV1020 would also be susceptible to antiviral chemotherapy with acyclovir. Indeed, in the current studies viral dissemination was only found in tumors by means of immunohistochemistry. This positive staining was found several cell layers deep from the tumor surface, indicating cell-to-cell spread of viral progeny. There was no immunohistochemical evidence of virus in adjacent normal intrathoracic tissues, specifically heart, lung, diaphragm, and chest 


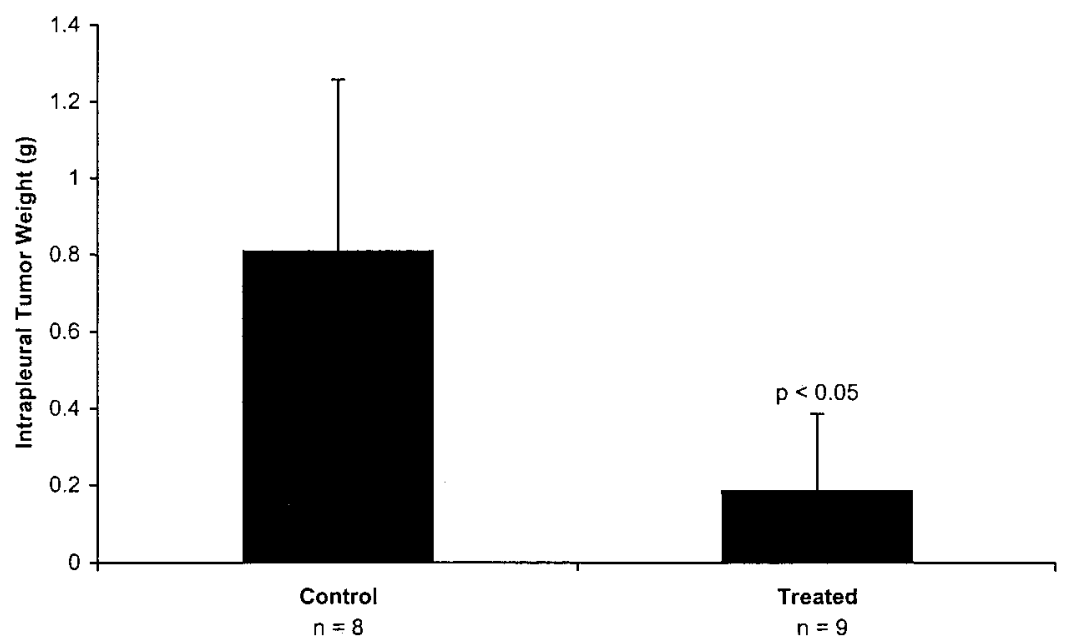

Figure 5. Mean intrapleural tumor weight in rats treated 3 days after tumor inoculation. Rats were treated with intrapleural PBS or intrapleural NV1020 $\left(1 \times 10^{7}\right.$ PFU). Error bars indicate SEM. $P$ value with a nonparametric Wilcoxon test is .046 .

wall. Furthermore, rats displayed no neurologic symptoms, such as paralysis or ataxia, and gained weight throughout the experimental period. These data would be consistent with previous data demonstrating that this and other $\gamma_{1} 34.5$ mutant viruses can be injected into many rodent models of cancer, with only minimal detection of virus in neural tissue and no discernable neurologic deficits. ${ }^{69}$ Furthermore, the current virus has been delivered into the brain of primates sensitive to wild-type virus with much reduced toxicity. ${ }^{12}$ Two different $\gamma_{1} 34.5$ mutant viruses are also delivered by means of direct injection into brain tumors in human trials, with no current evidence of viral dissemination in noncancerous tissues. ${ }^{22}$

With the use of 3 viral concentrations, the human lung adenocarcinoma cell line A549 proved susceptible to infection and lysis by NV1020. Even at an MOI of 0.01, NV1020 killed $66 \%$ of the cells by day 7 . This suggests that replication and subsequent infection by progeny virions also occurred. This is similar to the finding of Kucharczuk and colleagues, ${ }^{10}$ who found that A549 was susceptible to another HSV-1-based oncolytic virus, HSV-1716. The viral growth assay confirms that A549 efficiently supports NV1020 replication, indicating a viral burst at 48 hours after infection. This correlates with the increase in cell death at 48 to 72 hours seen in the cytotoxicity assay.

Two clinical situations were mimicked by our model to evaluate the efficacy of NV1020 in vivo. In the first scenario we set out to treat free tumor cells in the pleural cavity, simulating a malignant effusion. A tumor cell suspension was introduced into the pleural cavity, and the animals were treated 3 hours later through 2 different routes. Intravenous therapy proved to be ineffective in this experiment. This is most likely the result of several factors. First, the tumor cells were certainly not vascularized at this point. Second, NV1020 is rapidly cleared from the bloodstream after intravenous injection, ${ }^{12}$ leaving little virus to extravasate into the pleural cavity. It is possible, however, that systemic delivery might have proven efficacious had our sample size been greater. Intrapleural regional therapy, on the other hand, was extremely effective. Direct injection into the pleural space has the theoretic advantage of increasing the concentration of virus at the site of disease, thereby maximizing the therapeutic effect while minimizing systemic toxicities. This particular experiment demonstrated the efficacy of NV1020 for the treatment of free-floating tumor cells in the pleural space and encourages future clinical testing of this virus in conjunction with resection for advanced local lung cancer where free pleural shedding of tumor is likely.

The final common pathway of malignant pleural fluid formation is impaired lymphatic drainage from the pleural space. ${ }^{23}$ This is caused by gross tumor infiltration of parietal pleural stomata, obstruction of mediastinal nodes, and obstruction of lymphatics. This scenario of gross disease is modeled by our second in vivo experiment, in which animals were treated 3 days after intrapleural introduction of tumor. At 3 days, animals have gross tumors on the pleura, chest wall, and diaphragm, as well as microscopic disease within the mediastinal fat. These tumor locations are similar to clinical findings of pleural metastatic lesions in patients. ${ }^{24}$ We show that NV1020 inhibits progression of gross disease within the pleural cavity. The results of this experiment, as expected, were less striking than results obtained in experimental treatment of microscopic disease. It is likely that, on multiple administrations of virus, a more pronounced effect might be seen. ${ }^{11}$ Furthermore, because oncolytic viral ther- 
apy works by means of mechanisms distinct from conventional therapies, cancers that are chemoresistant or radioresistant might be susceptible to virus. ${ }^{25}$

NV1020 efficiently kills human lung cancer lines in vitro and is effective in reducing tumor burden in a rat model of pleural cancer. Moreover, NV1020 appears to be safe when administered through the intrapleural route in rats. These initial results encourage further studies with NV1020 for the treatment of pleural cancers, both metastatic and primary.

We thank Yong-Jia You for excellent technical assistance and Dr Katia Manova for her advice.

\section{References}

1. Johnston WW. The malignant pleural effusion. A review of cytopathologic diagnoses of 584 specimens from 472 consecutive patients. Cancer. 1985;56:905-9.

2. DiBonito L, Falconieri G, Colautti I, Bonifacio D, Dudine S. The positive pleural effusion: a retrospective study of cytopathologic diagnoses with autopsy confirmation. Acta Cytol. 1992;36:329-32.

3. Figlin R, Mendoza E, Piantadosi S, Rusch VW. Intrapleural chemotherapy without pleurodesis for malignant pleural effusions. Chest. 1994;106(suppl 6):363S-6S.

4. Tohda Y, Iwanaga T, Takada M, Kawahara M, Negoro S, Okishio K, et al. Intrapleural administration of cisplatin and etoposide to treat malignant pleural effusions in patients with non-small cell lung cancer. Chemotherapy. 1999;45:197-204.

5. Markert JM, Gillespie GY, Weichselbaum RR, Roizman B, Whitley RJ. Genetically engineered HSV in the treatment of glioma: a review. Rev Med Virol. 2000;10:17-30.

6. Bennett JJ, Kooby DA, Delman K, McAuliffe P, Halterman MW, Federoff $\mathrm{H}$, et al. Antitumor efficacy of regional oncolytic viral therapy for peritoneally disseminated cancer. J Mol Med. 2000;78: $166-74$.

7. Carew JF, Kooby DA, Halterman MW, Federoff HJ, Fong Y. Selective infection and cytolysis of human head and neck squamous cell carcinoma with sparing of normal mucosa by a cytotoxic herpes simplex virus type 1. Hum Gene Ther. 1999;10:1599-606.

8. Coukos G, Makrigiannakis A, Montas S, Kaiser LR, Toyozumi T, Benjamin I, et al. Multi-attenuated herpes simplex virus-1 mutant G207 exerts cytotoxicity against epithelial ovarian cancer but not normal mesothelium and is suitable for intraperitoneal oncolytic therapy. Cancer Gene Ther. 2000;7:275-83.

9. Kooby D, Carew J, Halterman M, Mack J, Bertino J, Blumgart LH, et al. Oncolytic viral therapy for human colorectal cancer and liver metastases using a multi-mutated herpes simplex virus type-1 (G207). FASEB J. 1999;13:1325-34.

10. Kucharczuk JC, Randazzo B, Chang MY, Amin KM, Elshami AA, Sterman DH, et al. Use of a "replication-restricted" herpes virus to treat experimental human malignant mesothelioma. Cancer Res. 1997; 57:466-71.

11. Walker JR, McGeagh KG, Sundaresan P, Jorgensen TJ, Rabkin SD, Martuza RL. Local and systemic therapy of human prostate adenocarcinoma with the conditionally replicating herpes simplex virus vector G207. Hum Gene Ther. 1999;10:2237-43.

12. Meigner B, Martin B, Whitley RJ, Roizman B. In vivo behavior of genetically engineered herpes simplex viruses R7017 and R7020. II.
Studies in immunocompetent and immunosupressed owl monkeys (Aotus trivirgatus). J Infect Dis. 1990;162:313-20.

13. Heike Y, Takahashi M, Ohira T, Naruse I, Hama S, Ohe Y, et al. Genetic immunotherapy by intrapleural, intraperitoneal, and subcutaneous injection of IL-2 gene-modified Lewis lung carcinoma cells. Int J Cancer. 1997;73:844-9.

14. McLemore TL, Eggleston JC, Shoemaker RH, Abbott BJ, Bohlman ME, Liu MC, et al. Comparison of intrapulmonary, percutaneous intrathoracic, and subcutaneous models for the propagation of human pulmonary and nonpulmonary cancer cell lines in athymic nude mice. Cancer Res. 1988;48:2880-6.

15. Nagamachi Y, Tani M, Shimizu K, Tsuda H, Niitsu Y, Yokota J. Orthotopic growth and metastasis of human non-small cell lung carcinoma cells injected into the pleural cavity of nude mice. Cancer Lett. 1998;127:203-9.

16. Delman K, Bennett J, Zager JS, Burt BM, McAuliffe P, Petrowsky H, et al. Effects of preexisting immunity on the response to herpes simplex based oncolytic viral therapy. Hum Gene Ther. 2000;11:246572.

17. Meigner B, Longnecker R, Roizman B. In vivo behavior of genetically engineered herpes simplex viruses R7017 and R7020: construction and evaluation in rodents. $J$ Infect Dis. 1988;158:602-14.

18. Kucharczuk JC, Elshami AA, Zhang HB, Smythe WR, Hwang HC, Tomlinson JS, et al. Pleural-based mesothelioma in immune competent rats: a model to study adenoviral gene transfer. Ann Thorac Surg. 1995;60:593-8.

19. Sahn SA, Good JT. Pleural fluid pH in malignant effusions. Diagnostic, prognostic, and therapeutic implications. Ann Intern Med. 1988; 108:345-9.

20. Chernow B, Sahn SA. Carcinomatous involvement of the pleura. Am J Med. 1977;63:695-702

21. Albelda SM, Wiewrodt R, Zuckerman JB. Gene therapy for lung disease: hype or hope? Ann Intern Med. 2000;132:649-60.

22. Markert JM, Medlock MD, Rabkin SD, Gillespie GY, Todo T, Hunter WD, et al. Conditionally replicating herpes simplex virus mutant G207 for the treatment of malignant glioma: results of a phase I trial. Gene Ther. 2000;7:867-74.

23. Reed CE. Management of the malignant pleural effusion. In: Pass HI, Mitchell JB, Johnson DH, Turrisi AT, editors. Lung cancer: principles and practice. Philadelphia: Lippincott-Raven Publishers; 1996. p. 64354.

24. Canto A, Ferrer G, Romagosa V, Moya J, Bernat R. Lung cancer and pleural effusion: clinical significance and study of pleural metastatic locations. Chest. 1985;87:649-52.

25. Advani SJ, Chung S-M, Yan SY, Gillespie GY, Markert JM, Whitley $\mathrm{RJ}$, et al. Replication-competent, nonneuroinvasive genetically engineered herpes virus is highly effective in the treatment of therapyresistant experimental human tumors. Cancer Res. 1999;59:2055-8.

\section{Discussion}

Dr Robert J. Ginsberg (Toronto, Ontario, Canada). Was that a sham experiment?

Dr Ebright. I assume you are asking me about the animal treatment efficacy experiments. Both experimental and control animals were administered the same concentration of intrapleural tumor at day 0. Experimental animals were treated with intrapleural virus, and control animals were treated with an identical volume of intrapleural saline solution. 